\title{
A SWASH-ZONE SEAWARD BOUNDARY CONDITION FOR IMPERMEABLE BEACHES
}

\author{
Anton Ali ${ }^{1 *}$ and Deborah Villarroel-Lamb ${ }^{2}$ \\ ${ }^{1,2}$ Faculty of Engineering, The University of the West Indies, Trinidad \\ ${ }^{1}$ Email: anton_1991@live.com* \\ 2Email: deborah.villarroel-lamb@sta.uwi.edu
}

\begin{abstract}
Numerical Modelling of the swash-zone has received considerable attention in recent years in an effort to better predict the hydrodynamics of this coastal zone subsection. State of the art numerical models typically employ the well-known Navier-Stokes equations or one of its variations. Consequently, suitable boundary conditions are needed for such models to ensure that real-life applications are simulated whilst also reducing the computational effort. This paper presents an empirically derived sea-ward boundary condition at the initial still water line position of the zone. The boundary condition is developed via laboratory experiments which simulate regular linear incident wave climates upon impermeable and variable beach slopes. The developed boundary condition favorably mimics experimental data and better predicts swash flow depths and velocities at the initial still water line when compared to more well-established models.
\end{abstract}

Keywords: Impermeable beach, Seaward boundary condition, Swash-zone, Wave climate.

https://doi.org/10.47412/OEDT3765

\section{Introduction}

The swash-zone is the region of the beach which is periodically wetted due to induced wave action and more commonly defined by the run-up and run-down limits of the shoreline position. This zone is of particular importance due to two main considerations: (1) it possesses the largest sediment budget of the nearshore zone, and (2) it can be considered the most dynamic zone of this region [1]. The oscillating run-up and run-down of the shoreline is termed the swash event and can be broken into the uprush and backwash phases. In general, the hydrodynamics between each are significantly different. Comparatively, higher maximum velocities are typical of the uprush phase, whilst longer flow periods are typical of the backwash phase [2]. Despite the generic differences between uprush and backwash, the overall hydrodynamics of the swash event is strongly influenced by whether breaking or non-breaking waves occur at the shore [1]. This occurrence or non-occurrence is dependent on offshore wave conditions and shoreface parameters. More specifically, it can be stated that swash hydrodynamics is governed by offshore wave conditions, as well as beach slope and constituent sediment size [3]. These parameters are highly variable; wave conditions may vary across infra-gravity (30-300 sec period) and gravity (0.3-30 sec period) scales [4]; beach slopes may range across varying degrees of steepness; sediment size may range from fine sands to boulders [5]. 
In-situ investigation of swash hydrodynamics is difficult due to the temporal and spatial variability of natural swash events. Consequently, both numerical and physical modelling of the zone have been pursued where a typical reduction to a single swash cycle within models is assumed by many researchers [3]. Earliest numerical models can be dated to the 1950s (e.g. [6], [7] and [8]). These models predominantly employ the depth-averaged nonlinear shallow-water theory or Boussinesq simplifications and have significantly advanced understanding of the swash-zone. Nonetheless, the complex processes of the zone's hydrodynamics are not completely understood, warranting the need for further in-depth investigations [2]. Alternatively, depth-resolving models, which implement some form of the full Navier-Stokes Equations, presents a viable option for an improved flow description in the zone. Earliest implementations can be dated to 1984 for simulations done by Svendsen and Madsen [9]. To date, such models have contributed to turbulence, bore collapse and infiltration/exfiltration effects within the zone. However, the significant improvements in accuracy and flow detailing provided by such models are associated with an increase in computational cost [10].

Therefore, it appears desirous to pursue any technique which can reduce the computational cost of such models within the zone. This paper presents one such mechanism in the form of a simplified presentation of the seaward boundary condition. This boundary is applied at the geophysical Still Water Line (SWL) position of the beach foreshore, for limited wave conditions. Although the dam break problem has historically been used as the initial boundary condition at the SWL for a single swash event generated by a collapsing bore, [11] and [9] have outlined observable discrepancies with this analogy. Additionally, the dam break boundary condition is applicable for a single swash event and does not directly/indirectly consider any reflected energy or superposition due to previous swash cycles. In contrast, the novel boundary condition developed by the authors is derived from periodic regular waves within the gravity wave band. Hence, it indirectly encompasses any possible superposition between backwash and up-rush energy seaward of the zone. It should be noted however that the developed boundary condition is limited to non-breaking waves at the SWL, as well as, breaking waves seaward of the SWL position.

Section 2 gives a brief overview of typical hydrodynamic models used in the zone, with a specific focus on depth-integrated and depth-resolving models. Section 3 outlines the experimental set-up and methodology used to develop the novel boundary condition. Section 4 presents the results, post-processing and performance analysis of the developed boundary condition. Finally, Section 5 gives concluding remarks.

\section{Swash hydrodynamic models}

The water depths are very small in the swash-zone [12] and flows are incompressible and Newtonian, thus highlighting the suitability of the Navier-Stokes Equations (NSE) [10]. Previous theoretically based swash hydrodynamic models have applied simplifications to the full NSE. The result are models which utilize the Boussinesq type equations or Non-linear Shallow Water Equations (NSWE). Comparatively between these, the NSWE are better suited for shallow flows [13]. Hence, most simplified models apply the NSWE. In addition to these simplified models, empirical and semi-empirical models have also been developed for the zone. Baldock and Holmes (1997), ([14]), is one such semi-empirical model that has produced acceptable results for steep beaches. Brief details of the NSE, NSWE and the Baldock and Holmes models are presented in this section. 


\subsection{Navier-Stokes Equations (NSE)}

The NSE, Eqs. (1) and (2) (conservative form), are generally understood as Newton laws of motion applied to fluids and comprise two partial differential equations.

$$
\begin{gathered}
\partial \rho / \partial \mathrm{t}+\nabla \cdot(\rho \overrightarrow{\mathrm{U}})=0 \\
\partial \rho \overrightarrow{\mathrm{V}} /_{\partial \mathrm{t}}+\nabla \cdot(\rho \overrightarrow{\mathrm{U}} \overrightarrow{\mathrm{U}})=-\nabla \mathrm{P}+\nabla \cdot(\tau)+\rho \cdot \mathrm{g}+\mathrm{F}
\end{gathered}
$$

Where: $\mathrm{P}, \rho$ and $\tau$ are the fluid pressure, density and viscous stress tensor respectively, $\overrightarrow{\mathrm{U}}$ is the fluid velocity vector, $\mathrm{F}$ is any other external forces acting on the fluid and $\mathrm{g}$ is the acceleration due to gravity. In general, solutions of NSE are so complex that analytical solutions exist for only a few simple cases [15]. Consequently, solutions to Eqs. (1) and (2) are largely pursued numerically under the branch of Computational Fluid Dynamics (CFD).

With regard to swash flows, the NSE must also be solved with an additional multiphase model due to the transient nature of the swash lens. Moreover, relevant closure models must be added when ensembled-averaged versions such as the Reynolds Averaged Navier-Stokes and Large Eddy Simulations are used to consider turbulent descriptions. As a result of such added descriptions, coupled with the depth resolving nature of Eqs. (1) and (2), NSE models are recognized to be crucial in better understanding swash flows. Popular examples of their use within the zone can be found in [9],[16], [17] and [18]. Unfortunately, solving Eqs. (1) and (2) depends heavily upon the availability of computational power due to the typical high computing costs associated with solving these equations [10].

\subsection{Non-linear Shallow Water Equations (NSWE)}

The NSWE, Eqs. (3) and (4) - (one dimensional), are hyperbolic partial differential equations, thus they possess characteristic curves which permit a reduction to simpler ordinary differential equations [13].

$$
\begin{gathered}
\partial[\mathrm{u}(\mathrm{\eta}+\mathrm{h})] / \partial \mathrm{x}+\partial \eta / \partial \mathrm{t}=0 \\
\partial \mathrm{u} / \partial \mathrm{t}+\mathrm{u} \cdot \partial \mathrm{u} / \partial \mathrm{x}+\mathrm{g} \cdot \partial \eta / \partial \mathrm{x}=0
\end{gathered}
$$

Where: $\mathrm{u}$ is the horizontal water velocity, $\mathrm{\eta}$ is the water surface elevation, $\mathrm{h}$ is the SWL level, $\mathrm{x}$ is the horizontal distance and $t$ is time. Swash flows originating from incident waves can be described via the full numerical implementation of Eqs. (3) and (4) with appropriate boundary conditions. However, analytical solutions for both non-breaking and breaking waves have been developed by Carrier and Greenspan (1958), ([4]) and Shen and Meyer (1963), ([8]) respectively. The Shen and Meyer model, Eq. (5), has received greater popularity; primarily due to the fact that 
breaking waves occur on most beaches [1]. Thus, details of the Carrier and Greenspan model are omitted here in favor of the detailing the Shen and Meyer model.

Equation (5) is a unique solution that describes the swash flow due to a single collapsing uniform bore at the SWL. Prior to collapse, this uniform bore would have been generated by broken waves further offshore [19]. The solution requires knowledge of the initial velocity at the shoreline $\left(\mathrm{U}_{0}\right)$, which is dependent on the nature of bore collapse and typically found by Eq. (6) [20]. The motion of the shoreline can be understood by fundamental ballistics and be mapped by a simple parabolic equation describing the leading fluid particle of the swash lens given by Eq. (7), [8], [4], [20].

$$
\begin{gathered}
h(x, t)=\left(X_{s}(t)-x\right)^{2} / 9 t^{2} \\
U_{0}=C \sqrt{g \cdot H_{B}}=\sqrt{2 g \cdot \sin (\beta) \cdot R_{\max }} \\
X_{S}(t)=U_{0} t-1 / 2 g t^{2} \sin \beta
\end{gathered}
$$

Where: $h(x, t)$ is the water depth (at location $x$ for time $t$ ), $H_{B}$ is the bore height at the point of collapse, $\mathrm{C}$ is a coefficient outlining the efficiency of bore collapse, $\beta$ is the beach slope, $\mathrm{X}_{\mathrm{s}}(\mathrm{t})$ is the shoreline location (at time $t$ ) and $R_{\max }$ is the maximum run-up distance relative to the SWL position. The Shen and Meyer model possesses many discrepancies and shortcomings. Firstly, the solution is valid only in the upper region of the swash close to the moving shoreline [1], whilst the internal hydrodynamics are less well described [21]. Secondly, the solution has been observed to predict earlier swash reversal and greater temporal asymmetry between up-rush and backwash phases than actually occurs [4], [22]. Lastly, the solution predicts swash flows which are hydrodynamically similar for all events, highlighting its negation of any momentum behind the bore front [3], and thus its independence on offshore conditions [1]. Nonetheless, reasonable comparisons between model predictions and in situ measurements have been observed [4]. Peregrine and Williams (2001), ([20]), also extended the model by describing corresponding flow velocities given by Eq. (8).

$$
u(x, t)=2 / 3 t\left(1 / 2 U_{o} t-g t^{2} \sin \beta+x\right)
$$

Where: $u(x, t)$ is the flow velocity (at a given location $x$ for a specific time $t$ ). The researchers also outlined Eq. (5) as one specific solution of the NSWE in characteristic form, with a constant value of $\alpha=2$ on the forward characteristic. This being equivalent to a dam break scenario at the SWL. Guard and Baldock (2007), ([21]), further extended on the work of Peregrine and Williams (2001), by suggesting a linear variation of $\alpha$ on the forward characteristic given by Eq. (9). This variation corresponds to different solutions of NSWE for varying seaward boundary conditions.

$$
\alpha(\mathrm{t})=2+\mathrm{k}(\mathrm{t})
$$


Where: $\alpha(\mathrm{t})$ is the value of the characteristic variable (at time $\mathrm{t}$ ) and $\mathrm{k}$ is an introduced constant introduced. Despite noteworthy improvements, the selection of $\mathrm{k}$ is subjective and without any significant physical meaning/relation to offshore wave conditions [2].

\subsection{Semi-Empirical Model- Baldock and Holmes (1997)}

The Baldock and Holmes 1997 model, ([14]), Eqs. (10) and (11) was proposed as an improved similarity solution for swash flows due to the limitations of Eq. (5). The model was developed from laboratory experiments on steep beach slopes. The model produces similar swash profiles for all swash events, analogous to the predictions of the Shen and Meyer model. However, in comparison to Eq. (5), Eq. (6) produces variations in water depth across the swash, depending on the empirical coefficients chosen [22].

$$
\begin{gathered}
h(x, t)=H_{B}\left(X_{s}-x / X_{s}\right)^{C}\left(T_{s}-t / T_{s}\right)^{D} \\
u(x, t)=V_{s}(t+\Delta t)-V_{s}(t-\Delta t) / 2 h(x, t) \Delta t
\end{gathered}
$$

Where: $\mathrm{C}$ and $\mathrm{D}$ are empirical coefficients within ranges (0.5-0.75) and (1-2) respectively, $\mathrm{V}_{\mathrm{s}}$ is the volume of water (shoreward of the location $\mathrm{x}$ ) and $\mathrm{T}_{\mathrm{S}}$ is the swash duration period.

\section{Experimental set-up and boundary condition development}

The details of the experiment set-up, its operation, and conditions upon which data were collected are presented in sub-section 3.1. The subsequent analysis and procedure used to develop the proposed boundary condition from this data is presented in sub-section 3.2.

\subsection{Laboratory Experiments}

The experiments were carried out in the Coastal Engineering flume in the Civil and Environmental Engineering Department at the University of the West Indies, St. Augustine Campus. The flume is $10 \mathrm{~m}$ long and $0.55 \mathrm{~m}$ wide and was used at a water depth of $0.35 \mathrm{~m}$ (Fig. 1). Smooth-hydrophobic impermeable beach slopes were installed $6.9 \mathrm{~m}$ from the wave generator (measured along the SWL) whilst capacitance wave gauges were deployed. High frame rate videos were taken along the glass walls of the flume; referenced against a uniform $1 \mathrm{~cm}$ grid parallel to the beach slope and zeroed at the intersection point between the SWL and beach slope (see Fig. 1 inset).

Regular linear waves at amplitudes ranging 0.01-0.03m for frequencies $0.1-1.2 \mathrm{~Hz}$ were used. Water level variations were measured at wave gauge locations. Simultaneously, video observations were made for the time-varying shoreline position parallel to the slope, as well as, the swash depths perpendicular to the beach slope. These conditions and observations were conducted for beach slopes which ranged $5^{\circ}-25^{\circ}$ at $5^{\circ}$ increments. 


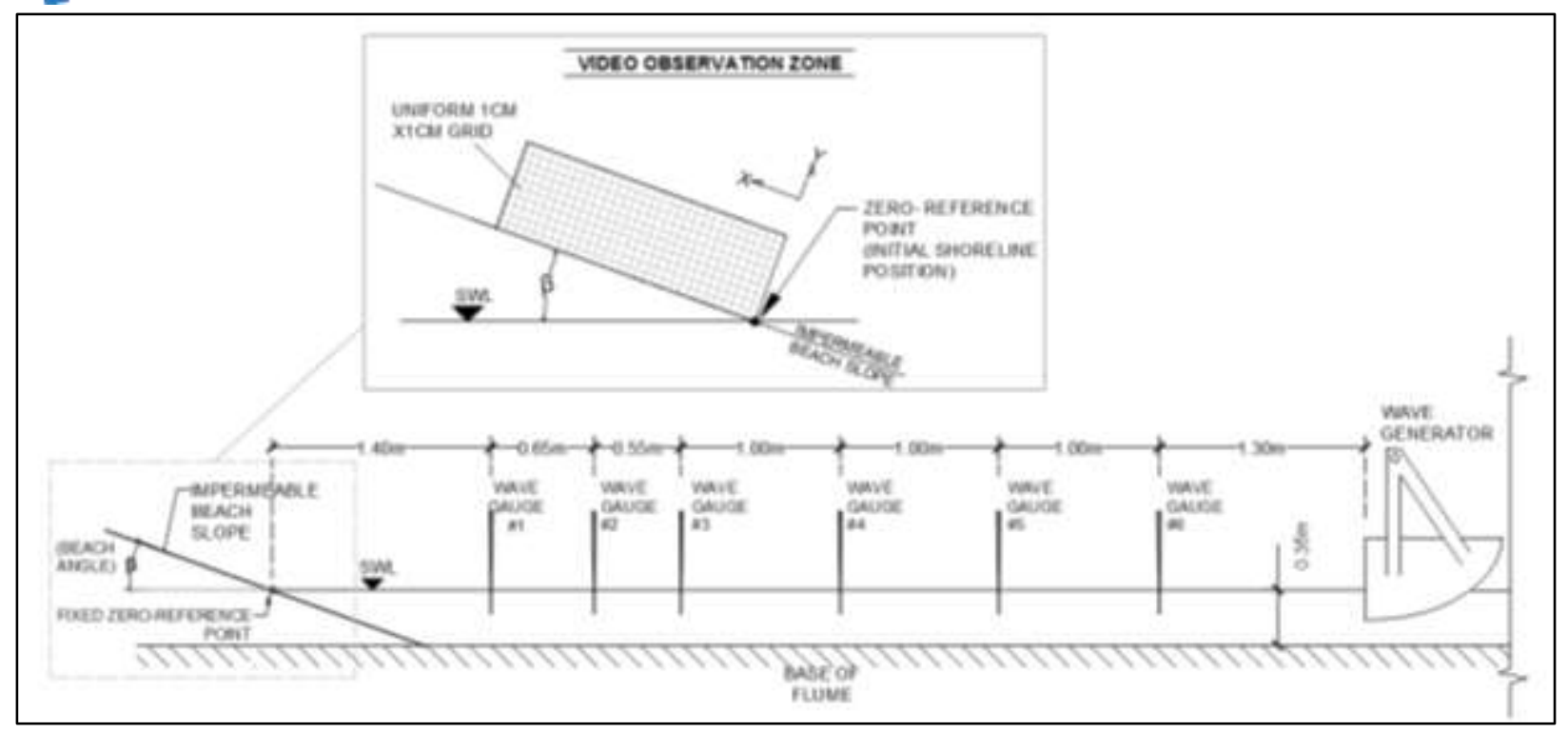

Figure 1: Laboratory experiment set-up.

\subsection{Post-processing and Boundary Condition Development}

Utilizing the equilibrium swash event for all wave conditions, time-referenced images were extracted from video observations at a frequency of $20 \mathrm{~Hz}$. Subsequently, swash depths were measured against the reference grid for the entirety of the swash film shoreward of the initial SWL position. Under the assumption of uniform depth across the flume channel as well as negligible surface tension effects, the temporal swash depth variation at the $\operatorname{SWL}, \mathrm{H}^{*}(0, \mathrm{t})$, was obtained directly. The temporal average flow velocity at the initial SWL position, $U^{*}(0, t)$, was also obtained via similar observations coupled with the application of equation (11).

Regression analysis of the results of both $H^{*}(0, t)$ and $U^{*}(0, t)$ across the various experimental conditions revealed a general sine curve fit for $\mathrm{H}^{*}(0, \mathrm{t})$, whilst no generalized relation for $\mathrm{U}^{*}(0, \mathrm{t})$ was observed. Alternatively, an analysis between $\mathrm{H}^{*}(0, \mathrm{t})$ and $\mathrm{U}^{*}(0, \mathrm{t})$ outlined a generic elliptical variation of $U^{*}(0, t)$ with $H^{*}(0, t)$ for all experimental wave conditions. More specifically, two (2) different ellipses, both centered at the origin $\left(\mathrm{U}^{*}(0, \mathrm{t})=0\right.$ and $\left.\mathrm{H}^{*}(0, \mathrm{t})=0\right)$ but lying in the $2^{\text {nd }}$ and $3^{\text {rd }}$ quadrants, were found to describe the uprush and backwash phases respectively. Linear wave theory was then used to convert the wave heights generated within the flume to their deep-water representations, assuming that only the shoaling transformation was applicable.

The Eureqa platform was then used to relate the coefficients of the sine fits for $\mathrm{H}^{*}(0, \mathrm{t})$ and the $\mathrm{U}^{*}(0, \mathrm{t})$ ellipse fits to the corresponding slope and deep-water wave parameters, essentially yielding the proposed boundary condition. Eureqa fits equations to datasets via evolutionary search procedures. Thus, the developed boundary condition was obtained over various equation possibilities. Lastly, the reflected energy for the wave conditions was computed from wave gauge readings to add further perspective to the results obtained. 


\section{Results and Analysis}

The proposed boundary condition which describes the temporal sine variation of $\mathrm{H}^{*}(0, \mathrm{t})$ over the entire swash event is given by Eqs. (12a) - (12d), whilst the elliptical variations of $U^{*}(0, t)$ for the up-rush and backwash phases of the swash are presented by Eqs. (13a) - (13e)

$$
\begin{aligned}
& H^{*}(0, t)=A_{1} \cdot \sin \left(B_{2} \cdot t+C_{3}\right) \\
& \mathrm{A}_{1}=158.15 \mathrm{~h}_{\mathrm{O}}+2.18 \mathrm{f}+1497.6 \beta \mathrm{h}_{\mathrm{O}}+\left(129.3 \mathrm{~h}_{\mathrm{O}}\right) / \mathrm{f}-0.68-519.97 \mathrm{f} \mathrm{h}_{\mathrm{O}}-5.58 \beta^{2}-18271.2 \mathrm{~h}_{\mathrm{O}}^{2} \\
& \mathrm{~B}_{2}=0.10+56.8 \mathrm{~h}_{\mathrm{O}}+6.7 \tanh (\mathrm{f})+4.9 \mathrm{f} \beta-2.65 \mathrm{f}-139.7 \mathrm{f} \mathrm{h}_{\mathrm{O}} \tanh (9021.2 \mathrm{f} \\
& \left.\mathrm{h}_{\mathrm{O}}{ }^{2}+6.7 \tanh (\mathrm{f}) \tan \left(9021.2 \mathrm{f}^{2}\right)\right) \\
& \mathrm{C}_{3}=0.03+0.87 \sin \left(\operatorname { s i n } \left(\operatorname { s i n } \left(\operatorname { t a n } \left(26.16 \mathrm{~h}_{\mathrm{O}}+139.8 \mathrm{~h}_{\mathrm{O}} \mathrm{f}^{2}+0.29 \mathrm{f} \tanh (\sin (13.7 \beta-0.3 \mathrm{f}))-263 \beta \mathrm{f}\right.\right.\right.\right. \\
& \left.\left.\left.\mathrm{h}_{\mathrm{O}}\right)\right)\right) \text { ) }
\end{aligned}
$$

Where: $\mathrm{f}$ is the frequency of incident waves, ho is the deep-water wave height and $\beta$ is beach slope in radians.

$$
\mathrm{H}^{*}(0, \mathrm{t})^{2} / \mathrm{a}^{2}+\mathrm{U}^{*}(0, \mathrm{t})^{2} / \mathrm{b}^{2}=1
$$

for the uprush:

$$
\begin{array}{r}
a=7.91 f-0.0124 / h_{O}+1463.27 \beta h_{O}+ \\
103.77 \beta h_{O} / f-1.15-4.11 \beta-3.74 \ln (f)-780.67 f h_{O} \quad(13 b) \\
b=K_{\text {up }}+19.6 f^{f}+332077 f^{2} h_{O}^{2} \sin (4798 f)+\tan \left(K+289629 h_{O}(19.6 f)^{f}-\beta\right)-\sin (4798 f)-73.4 \beta
\end{array}
$$

for the backwash:

$$
\begin{aligned}
& \mathrm{a}=\mathrm{f}+930.49 \beta \mathrm{h}_{\mathrm{O}}+130.77 \mathrm{~h}_{\mathrm{O}} / \mathrm{f}-0.50-31600.26 \mathrm{f} \mathrm{h}_{\mathrm{O}}{ }^{2}-158.9 \beta \mathrm{h}_{\mathrm{O}} \sin \left(204878942 \mathrm{~h}_{\mathrm{O}}\right) \\
& \mathrm{b}=\mathrm{K}_{\mathrm{bw}}-1.636 / \cos \left(\mathrm{K}_{\mathrm{bw}}\right)+\tan (297.78+10829.19 \beta \mathrm{f})-66.13 \beta-584167 \mathrm{fh}_{\mathrm{O}}{ }^{2}
\end{aligned}
$$

Where: $\mathrm{K}_{\mathrm{up}}=15.60+5660.69 \mathrm{~h}_{\mathrm{O}}$ and $\mathrm{K}_{\mathrm{bw}}=11437.91 \mathrm{~h}_{\mathrm{O}}+12484.87 \beta \mathrm{h}_{\mathrm{O}} \mathrm{f}^{3}$ 
Equations (13b) and (13d) outline the principal axis of the uprush and backwash ellipses respectively. The equations were expected to be similar in structure, if not congruent since they define the point of flow reversal. Physically, this value is the same for both phases of the swash event (i.e. $a_{u p}=a_{b w}$ when $U^{*}(0, t)=0$ ). However, subsequent to regression analyses, no such trend was observed. As a remedy, the average of Eqs. (13b) and (13d) is recommended to yield a congruent principal axis (a) value across both up-rush and backwash phases for each given case. Equations (12a) and (13a) have an overall good fit with the experimental data. Typical characteristic plots of $H^{*}(0, t)$ and $U^{*}(0, t)$ are provided in Fig. 2. Furthermore, Eqs. (12a) and (13a) have median $\mathrm{R}^{2}$ values of 0.93 and 0.83 respectively. Whilst the Eureqa fit models for constituent coefficient variability with $\beta$, ho and $\mathrm{f}$ (Eqs. (12b)-(12d) and Eqs. (13b)-(13e)) have a combined minimum $\mathrm{R}^{2}$ value of 0.92 where a maximum mean percentage error of $11 \%$ was observed for Eqs. (13c)-(13e) and 15\% was observed for Eq. (12d). Despite the relatively large mean error for the prediction of the $\mathrm{C}_{3}$ coefficient, an analysis of $\mathrm{H}^{*}(0, \mathrm{t})$ results revealed minimum sensitivity to this coefficient value.

Equations (12) - (13) were developed for swash events originating solely from non-breaking waves at the SWL as well as breaking waves seaward of this location. The visual method used by Eq. (11) imposes this restriction for waves that break shoreward, or at this reference point. The domain of validity for Eqs. (12) - (13) is given by the Eq. (14) which references the deepwater Iribarren number $\left(\xi_{\mathrm{O}}\right)$, Eq. (15). Values of $\xi_{\mathrm{O}}$ less than the righthand side of Eq. (14) outlines conditions that cannot be accurately described by the developed boundary conditions.

$$
\begin{array}{r}
\xi_{\mathrm{O}} \geq 0.167(\beta)+1.18 \quad \text { for } 5 \leq \beta \leq 25 \\
\xi_{\mathrm{O}}={ }^{\tan (\beta) / \sqrt{\mathrm{h}_{0} / \mathrm{L}_{0}}}
\end{array}
$$

Where: $\mathrm{L}_{0}=\frac{\mathrm{g}}{2 \pi} \mathrm{T}^{2}$ and $\mathrm{T}=$ wave period.

The results further provide the period between two successive equilibrium swash cycles. Assuming similar and repeating swash events, the period between the end of the backwash phase and the onset of a new-repeating swash event is given by Eq. (16).

$$
\mathrm{T}=0.017 \beta+\left(0.49+12.27 \mathrm{~h}_{0}\right) \mathrm{f}_{\mathrm{f}}+\cos (2.89 \mathrm{f}) /\left(\beta-5369.6 \mathrm{~h}_{0} \mathrm{f}\right)-0.44-25 \mathrm{~h}_{0}
$$

A total of 58 wave conditions across 5 slopes formed the basis of the developed boundary condition. Breaking waves accounted for 24 of these conditions. These waves broke within proximity of the intersection point between the beach slope and the initial SWL position. Consequently, a pronounced traveling turbulent bore which is typical of waves breaking further seaward was not observed. Nonetheless, utilizing the location at which the respective waves broke, the duration of the swash event and the maximum run-up position relative to this location, Eq. (6) 
yielded $\mathrm{U}_{\mathrm{O}}$ and $\mathrm{H}_{\mathrm{B}}$ upon which, the Shen and Meyer and Baldock and Holmes models were applied.

A comparison between the experimental results, the Shen and Meyer model, the Baldock and Holmes model and Eqs. (12) - (13) highlighted the poor performance of both the Shen and Meyer and Baldock and Holmes models for most of the 24 breaking wave conditions. At slopes greater than $10^{\circ}$, the Shen and Meyer model predicted shorter swash events with smaller backwash depths as compared to the experiments; an observation also noted by [4]. Conversely, the maximum swash depths compared reasonably with experimental results despite disparities for the time of occurrence.

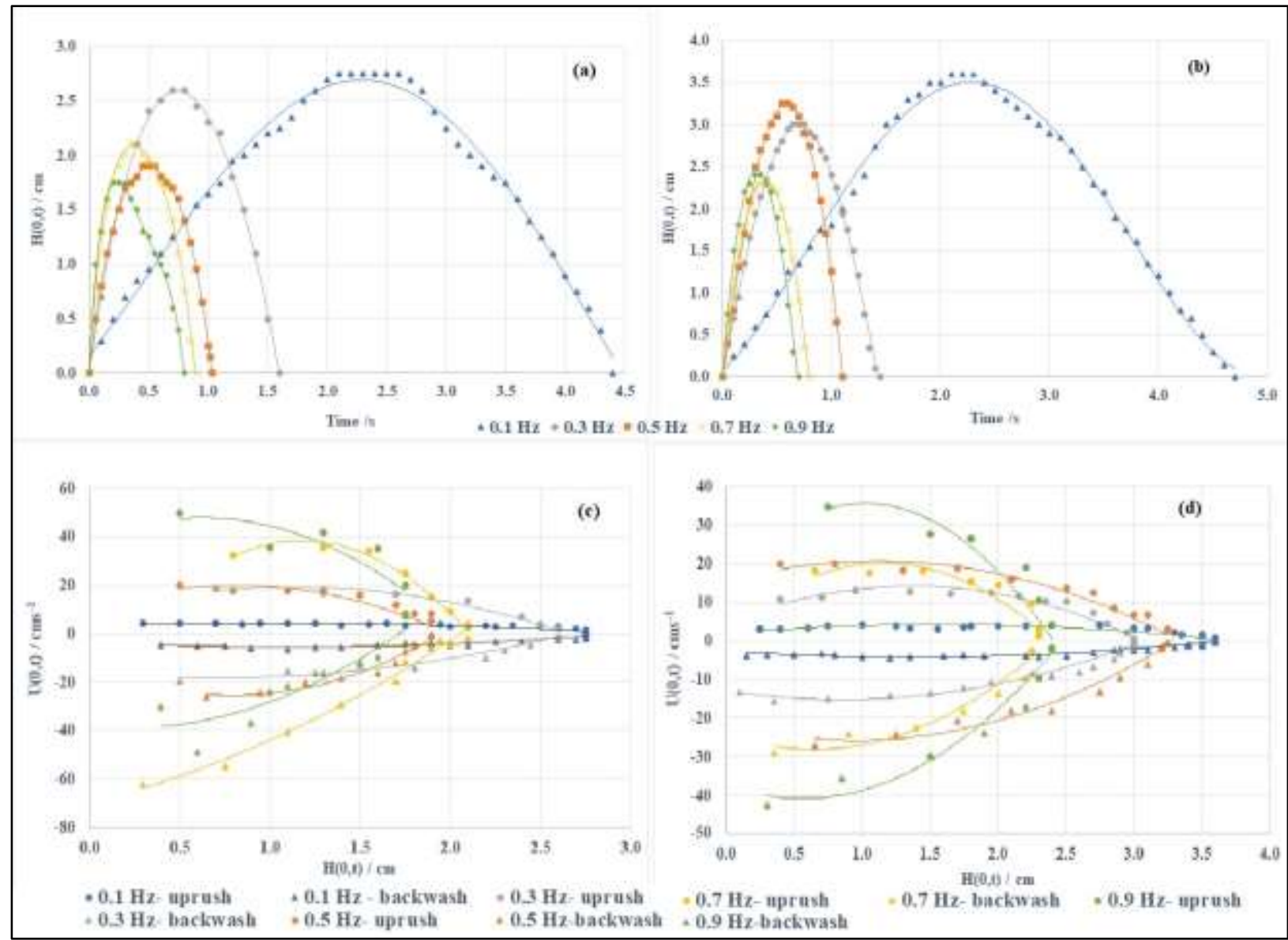

Figure 2: (a) Time variation of $\mathrm{H}(0, \mathrm{t})$ for $15^{\circ}$ slope $-0.01 \mathrm{~m}$ amplitude waves ranging $0.1-0.9 \mathrm{~Hz}$.

(b) Time variation of $\mathrm{H}(0, \mathrm{t})$ for $25^{\circ}$ slope $-0.01 \mathrm{~m}$ amplitude waves ranging $0.1-0.9 \mathrm{~Hz}$. (c)

Variation of $\mathrm{U}^{*}(0, \mathrm{t})$ with $\mathrm{H}^{*}(0, \mathrm{t})$ for $15^{\circ}$ slope $-0.01 \mathrm{~m}$ amplitude waves ranging $0.1-0.9 \mathrm{~Hz}$. (d) Variation of $\mathrm{U}^{*}(0, \mathrm{t})$ with $\mathrm{H}^{*}(0, \mathrm{t})$ for $25^{\circ}$ slope $-0.01 \mathrm{~m}$ amplitude waves ranging $0.1-0.9 \mathrm{~Hz}$. (N.B. waves measured at the generator).

Similar to the Shen and Meyer model, the Baldock and Holmes model also predicted shorter swash events than actually occurred. Further, the model consistently overpredicted swash depths for the uprush phase whilst underpredicted these depths for the backwash; This may be directly linked to the input bore height used via Eq. (6). Furthermore, although a constant combination of 0.75 and 
2 was used for the empirical coefficients $C$ and D across each of the 24 breaking wave conditions, experimentation with varying combinations of $\mathrm{C}$ and $\mathrm{D}$ did not yield improved results. With regards to temporal velocity predictions, both the Peregrine and Williams velocity extension of the Shen and Meyer model and Baldock and Holmes model poorly predicted velocities across swash events. Noting a few exceptions, both models generally underpredicted velocities during the uprush phase and overpredicted during the backwash phase. In contrast, Eqs. (12) - (13) compared favorably with the experimental results from which they were developed. Velocity profiles and swash depth comparisons yielded mean $\mathrm{R}^{2}$ values consistent with those outlined by the Eureqa fit. For breaking wave cases, both temporal depth and velocity profile predictions better replicate the experimental results as compared to the alternative models highlighted. For the 34 non-breaking wave cases, upon which neither the Shen and Meyer, Baldock and Holmes or Peregrine and Williams models can be applied, Eqs. (12) - (13) also compare favorably with experimental results. Fig. 3 provides characteristic plot comparisons between respective models and Eqs. (12) (13) for breaking wave cases.

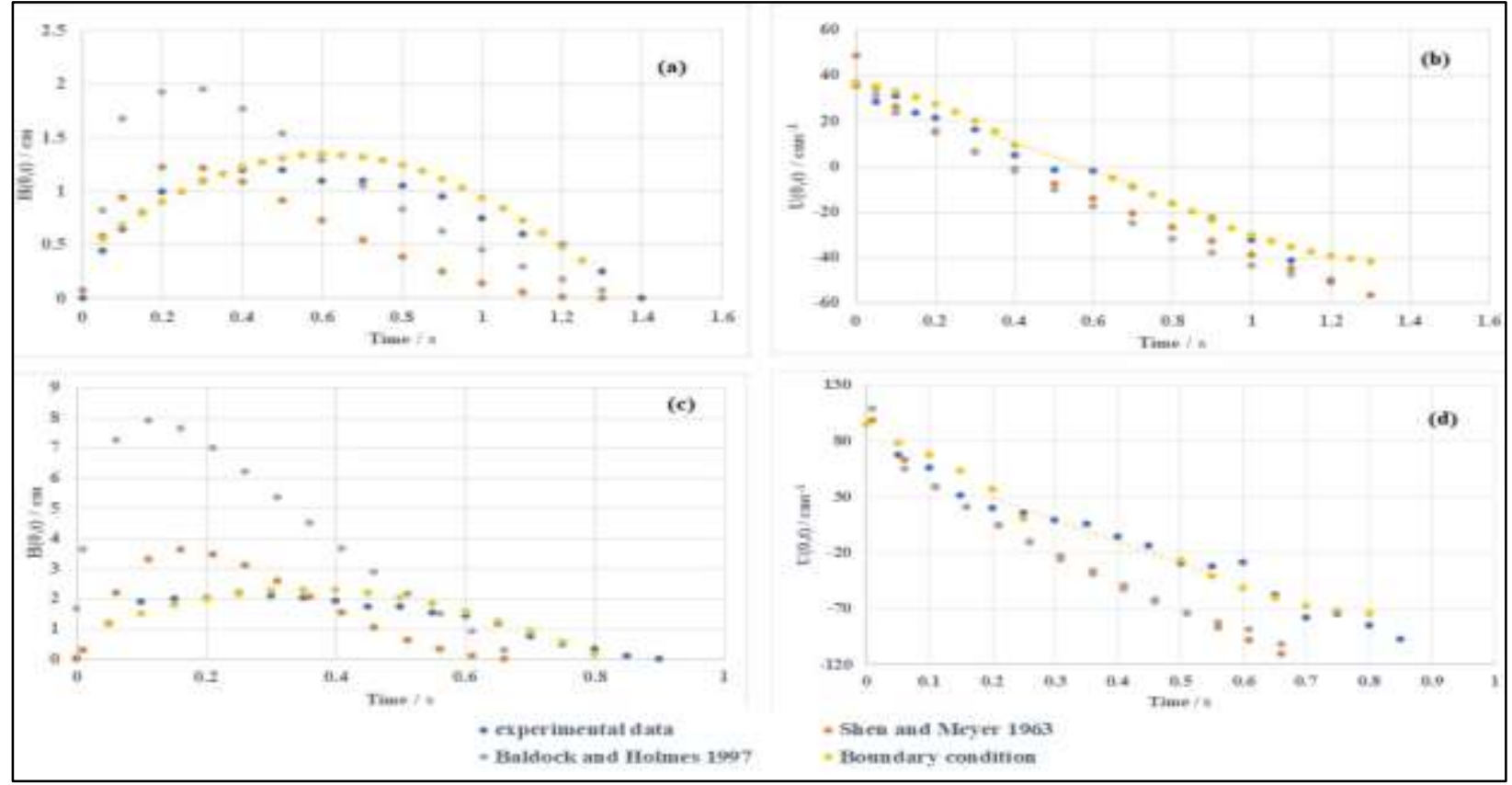

Figure 3: (a) Model comparisons of $\mathrm{H}(0, \mathrm{t})$ for $5^{\circ}$ slope $-0.01 \mathrm{~m}$ amplitude waves at $0.5 \mathrm{~Hz}$. (b) Model comparisons of $\mathrm{U}(0, \mathrm{t})$ for $5^{\circ}$ slope $-0.01 \mathrm{~m}$ amplitude waves at $0.5 \mathrm{~Hz}$. (c) Model comparisons of $\mathrm{H}(0, \mathrm{t})$ for $20^{\circ}$ slope $-0.02 \mathrm{~m}$ amplitude waves at $0.9 \mathrm{~Hz}$. (d) Model comparisons of $\mathrm{U}(0, \mathrm{t})$ for $20^{\circ}$ slope $-0.02 \mathrm{~m}$ amplitude waves at $0.9 \mathrm{~Hz}$. (N.B. breaking waves measured at the generator) 


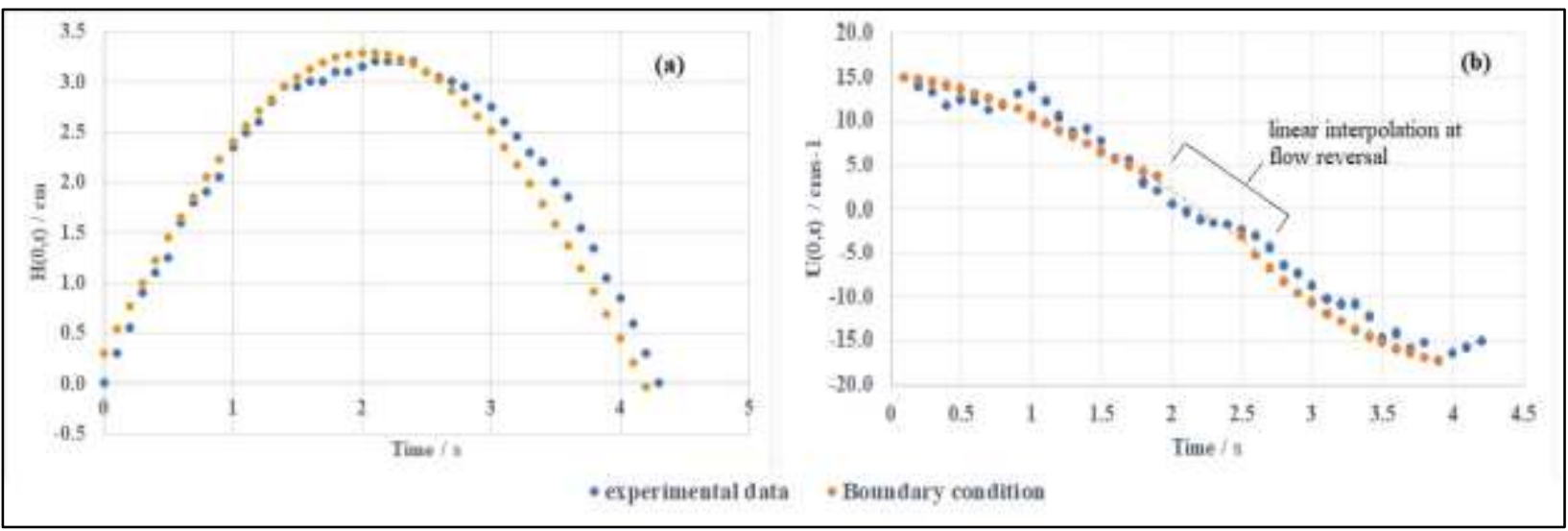

Figure 4: (a) Time variation of $\mathrm{H}(0, \mathrm{t})$ for $10^{\circ}$ slope $-0.01 \mathrm{~m}$ amplitude waves at $0.1 \mathrm{~Hz}$. (b) Time variation of $\mathrm{U}(0, \mathrm{t})$ for $10^{\circ}$ slope $-0.01 \mathrm{~m}$ amplitude waves at $0.1 \mathrm{~Hz}$. (N.B. non-breaking waves measured at the generator)

Two observable limitations are inherent in the developed boundary conditions. Firstly, due to the overall nature of Eq. (12a) and the imperfect fit of $\mathrm{C}_{3}$, swash depths are not accurately predicted less than $0.1 \mathrm{~s}$. Thus, a linear interpolation between the predicted value at $\mathrm{t}=0.1 \mathrm{~s}$ (obtained via Eqs. $(12 \mathrm{a})-(12 \mathrm{~d}))$ and $\mathrm{t}=0 \mathrm{~s}\left(\mathrm{H}^{*}(0,0)=0\right)$ is recommended. Secondly, Eqs. (13a) $-(13 \mathrm{e})$ may not accurately predict the flow velocity around the point of flow reversal. This is also due to the imperfect fits of the coefficient models for $b$. As a proposed solution, a linear interpolation within this region is recommended to ensure that reasonable predictions are obtained. Fig. 4 presents a typical comparison of Eqs. (12) - (13) with experimental data for a non-breaking wave case. The linear interpolation recommended at the point of flow reversal is shown.

Lastly, wave reflection analysis outlined an average reflection coefficient of 0.52 for all the 58 wave conditions utilized in the development of Eqs. (12) - (13). Median values of 0.31 were observed for breaking wave cases whilst 0.61 were observed for non-breaking waves. Although these values are high in comparison to typical in situ values, the values qualitatively agree with expected outcomes. Higher reflection coefficients show more wave energy reflected offshore in contrast to being dissipated as is evident for breaking cases. Eqs. (12) - (13) may be associated with slightly larger $h_{o}$ values as compared to the calculated values for which they were developed due to possible superposition between the incident and reflected waves.

\section{Conclusion}

Numerical modelling of the swash-zone has aided in complex and dynamic descriptions of the zone in recent years. In an attempt to reduce the computational demands of modelling the swashzone, this paper presents a novel boundary condition Eqs. (12) - (13) to be implemented at the seaward boundary of the zone. The condition describes the temporal swash depth, velocity and cyclic repetition of swash events induced by linear regular waves on impermeable beaches. For these cases, the need for simulating the driving wave conditions offshore of the zone is negated. This is foreseen to drastically reducing the computational demand associated with depth-resolving models of the zone. The boundary condition is valid for both non-breaking and breaking waves and indirectly accounts for swash-swash interactions due to the nature of its development. Despite this, it cannot describe swash events driven by waves that break shoreward of the initial SWL, hence the restriction of Eq. (14). Comparisons between the boundary condition and common semi- 
analytical/analytical models for breaking wave cases outlined similar predictions. However, compared to these models, the boundary condition better predicts the experimental data from which it was derived.

\section{References}

[1] D. M. Kelly, N. Dodd. Beach-face evolution in the swash-zone. Journal of Fluid Mechanics 661, (2010) 316-340.

[2] Z. Jiang. Swash-zone boundary conditions and direct shear stress measurements over loose sediment beds. Ph.D. Thesis, University of Queensland (2015).

[3] P. Chardón- Maldonado, J. C. Pintado-Patiño, J. A. Puleo. Advances in swash-zone research: Small scale hydrodynamics and sediment transport processes. Coastal Engineering 115, (2016) 825.

[4] M. G. Hughes. Application of a non-linear shallow water theory to swash following bore collapse on a sandy beach. Journal of Coastal Research 8 no. 3, (1992) 562-578.

[5] A. D. Short. Beaches, Physical Processes Affecting*. In Encyclopedia of Ocean Sciences (Second Edition). Edited J. H. Steele. 2001 (pp 305-315). Academic Press doi: 10.1016/B978012374473-9.00084-9.

[6] G. F. Carrier, H. P. Greenspan. Water waves of finite amplitude on a sloping beach. Journal of Fluid Mechanics 4 no. 1, (1958) 97-109.

[7] G. B. Whitham. On the propagation of shock waves through regions of non-uniform area or flow. Journal of Fluid Mechanics 4 no. 4, (1958) 337-360.

[8] M. C. Shen, R. E. Meyer. Climb of a bore on a beach Part 3. Run-up. Journal of Fluid Mechanics 16 no. 1, (1963) 113-125.

[9] M. Mory, S. Abadie, S. Mauriet, P. Lubin. Run-up flow of a collapsing bore over a beach. European Journal of Mechanics B/Fluids 30, (2011) 565- 576.

[10] R. Briganti, A. Tores-Freyermuth, T. E. Baldock, M. Brocchini, N. Dodd, T. Hsu, Z. Jiang, Y. Kim, J. C. Pintado-Patiño, M. Postacchini. Advances in numerical modelling of swash-zone dynamics. Coastal Engineering 115, (2016) 26-41.

[11] H. H. Yeh, A. Ghazali, I. Marton. Experimental study of bore run-up. Journal of Fluid Mechanics 206, (1989) 563-578.

[12] S. R. Massel, E. N. Pelinovsky. Run-up on dispersive and breaking waves on beaches. Oceanologia 43 no. 1, (2001) 61-97.

[13] M. Brocchini, N. Dodd. Nonlinear shallow water equation modelling for coastal engineering. Journal of Waterway Port Coastal and Ocean Engineering 134 no. 2, (2008) 104-120.

[14] T. E. Baldock, P. Holmes. 1997. Swash Hydrodynamics on a Steep Beach. In Coastal Dynamics '97 (pp. 784-793). A.S.C.E.. New York.

[15] T. Krüger, H. Kusumaatmaja, A. Kuzmin, O. Shardt, G. Silva, E. M. Viggen. 2017. The Lattice Boltzmann Method. Springer International Publishing.

[16] I. A. Svendsen, P. A. Madsen. A turbulent bore on a beach. Journal of Fluid Mechanics 148, (1984) 73-96.

[17] Q. Zhang, P. L.-F. Liu. A numerical study of swash flows generated by bores. Coastal Engineering 55 no. 12, (2008) 1113-1134.

[18] J. C. Pintado-Patiño, A. Torres-Freyermuth, J. A. Puleo, D. Pokrajac. On the role of infiltration and exfiltration in swash-zone boundary layer dynamics. Journal of Geophysical Research: Oceans 120 no. 9, (2015) 6329-6350. 
[19] D. H. Peregrine, S.M. Williams. Swash overtopping a truncated plane beach. Journal of Fluid Mechanics 440, (2001) 391-399.

[20] T. E. Baldock, P. Holmes. Simulation and prediction of swash oscillations on a steep beach. Coastal engineering 36, (1999) 219- 242.

[21] P. A. Guard, T. E. Baldock. The influence of seaward boundary conditions on swash-zone hydrodynamics. Coastal Engineering 54, (2007) 321-331.

[22] T. E. Baldock, M. G. Hughes, K. Day, J. Louys. Swash overtopping and sediment overwash on a truncated beach. Coastal Engineering 52, (2005) 633-645. 